\title{
Perspective
}

Expert insights on a timely policy issue

\section{THE DAYS AFTER}

\section{A DEAL WITH IRAN}

\section{IMPLICATIONS FOR THE NUCLEAR NONPROLIFERATION REGIME}

\section{Jeffrey M. Kaplow and Rebecca Davis Gibbons}

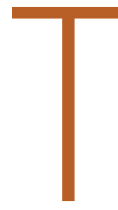

his analysis begins by positing that a final nuclear agreement is reached between Iran and the United States, Great Britain, France, Russia, China, and Germany (P5+1). One of a series of RAND perspectives on what the Middle

East and U.S. policy might look like in "the days after a deal," this Perspective examines the deal's implications for the nuclear nonproliferation regime. ${ }^{1}$ Slowing or stopping Iran's nuclear development is an important nonproliferation accomplishment, but the interna- tional community will need to find ways to mitigate some of the deal's negative consequences.

Although the parties have struggled to come to a final agreement, recently extending the deadline for talks, the broad outlines for a nuclear agreement are in place. Without predicting that a deal will ultimately be signed, the potential for reaching an agreement is great enough to warrant planning for such an outcome. (See the box on p. 2 for the assumed terms of an agreement.) ${ }^{2}$

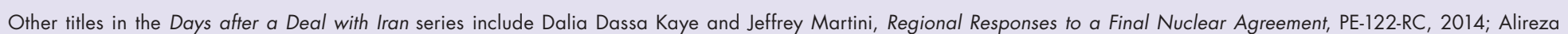

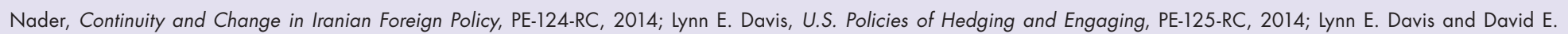

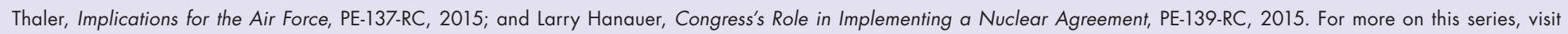
http://www.rand.org/international/cmepp/the-days-after-a-deal-with-iran.html 
The nuclear nonproliferation regime is the set of institutions and agreements aimed at preventing the spread of nuclear weapons. Its cornerstone, the Treaty on the Non-Proliferation of Nuclear Weapons (NPT), boasts near universal membership: Only four statesIndia, Pakistan, Israel, and newly independent South Sudan-have never signed, while North Korea withdrew from the treaty in 2003. Many analysts have credited the NPT with a substantial role in limiting nuclear proliferation since it entered into force in 1970. Under the treaty, non-nuclear weapons states agree not to develop or possess nuclear weapons in exchange for access to peaceful nuclear technology and the promise that all states will pursue good-faith efforts toward disarmament. To verify that nuclear technology is not being used for weapons purposes, states conclude nuclear safeguards agreements with the International Atomic Energy Agency (IAEA), allowing inspectors to verify their declarations and monitor nuclear facilities and activities. When the Board of Governors of the IAEA finds states to be in noncompliance with their agreements, such findings are reported to the United Nations (UN) Security Council. It was such a referral of Iran's case in 2006 that led to the series of sanctions that ultimately helped bring Iranian leaders to the negotiating table in earnest in 2013.

A completed deal with the Iranians represents good news for the nuclear nonproliferation regime overall. An agreement will reassure some states about the effectiveness of the regime and could contribute to stronger IAEA safeguards in the future, offering inspectors a better chance of detecting undeclared nuclear activities. At the same time, however, an agreement will almost certainly allow Iran to maintain a uranium enrichment capability. This may tempt some states to expand their nuclear infrastructure as part of a hedging strategy. A nuclear agreement with Iran also effectively

\section{Assumptions About the Contours of a Final Deal*}

For the purposes of analysis, the authors presume that if a final deal is reached between the P5+1 and Iran, it will be based on these general principles:

- Iran may continue to enrich uranium, but limits are placed on the degree of enrichment, and on the number and types of centrifuges used.

- Iran redesigns its Arak heavy water reactor to produce less plutonium in its spent fuel.

- Iran allows intrusive IAEA inspection of nuclear sites; Iran agrees to sign and ratify the Additional Protocol to its safeguards agreement, permitting IAEA access to nondeclared sites with little notification.

- Iran shares information with IAEA on possible military dimensions of the program.

- The United States and its partners phase out nuclear-related sanctions as agreement is implemented.

* These principles are derived from the elements for a comprehensive solution found in the Joint Plan of Action, signed by Iran and the P $5+1$ in Geneva on November 24, 2013. We are not predicting what the actual agreement will look like, but using these plausible contours as a point of departure for our analysis. 
legitimizes a domestic nuclear infrastructure that was built despite Iran being found in noncompliance with its agreements under the NPT. These downsides to a deal could pose additional challenges to the credibility of the nuclear nonproliferation regime and potentially ease the path for nuclear pursuit by other states in the future. ${ }^{3}$

A deal with Iran does more to strengthen the nonproliferation regime than to harm it, but the international community would do well to recognize the costs of this approach and seek ways to mitigate any damage. In the face of the negative precedent set by a deal, the United States should work to limit the further spread of enrichment and reprocessing (ENR) capabilities and focus new attention on the importance of enhanced IAEA safeguards measures. Ultimately, efforts to promote the long-term success of a deal will go a long way toward strengthening the regime itself.

In this Perspective, we describe the benefits of an Iran deal for the nuclear nonproliferation regime, then turn to an analysis of the costs for the regime, including the negative precedent set by allowing Iran to maintain a uranium enrichment capability. A deal with Iran may make it more difficult to limit the spread of ENR technology. We explore this possibility in the context of U.S.-South Korean relations, in which Seoul's access to sensitive nuclear technology has become a key point of contention. Finally, we conclude with policy recommendations for mitigating negative aspects of a nuclear agreement with Iran.

\section{The Benefits of an Iran Nuclear Deal for the Nuclear Nonproliferation Regime}

A nuclear agreement with Iran would represent a success for the nonproliferation regime in several ways. Most fundamentally, a deal offers at least the prospect of a sustainable resolution of the
Iranian nuclear issue. It is hard to overstate the importance of this result for the regime as a whole. The Iran nuclear case has been the central preoccupation of U.S. nonproliferation policy-and that of multilateral bodies such as the IAEA Board of Governors-for more than a decade. The unyielding emphasis on Iran has been central to U.S. efforts to mobilize broad support, first for a finding of noncompliance with the NPT, and later for robust international sanctions. But this strategy has sidelined discussion of other important nonproliferation issues, including efforts to bolster nuclear security, promote universal adherence to the Additional Protocol, and find a solution to the loophole of NPT withdrawal. And it has complicated relations with some states, particularly those that have been active in the Non-Aligned Movement, as the United States exerted pressure on them to support its votes on Iran in the IAEA and the United Nations. ${ }^{4}$ A deal with Iran could thus lead to a welcome turning of the page in U.S. nonproliferation efforts. Of course, a deal does not make the Iran nuclear issue go away, but it may help to put it on a more stable and sustainable footing. If Iran's nuclear program is no longer seen as a crisis, it may allow the United States and like-minded states to act more strategically on other important nonproliferation issues.

A nuclear agreement with Iran also would increase the credibility of the regime as a whole. A deal sends an important message to the international community: The nonproliferation regime may be
A deal sends an important message
to the international community: The nonproliferation regime may be messy, but it works. 


\section{An agreement with Iran may also have the desirable side effect of raising the profile of the Additional Protocol and other enhanced safeguards measures.}

messy, but it works. Some in the nonproliferation community have spent the last several years sounding the alarm about the decline of the regime. 5 These analysts argue that the continued pursuit of nuclear weapons by state parties to the NPT makes others more likely to violate the regime in the future. Behind this argument is the idea that dwindling confidence in the ability of the nonproliferation regime to constrain state behavior threatens to undermine states' collective commitment to foreswear nuclear weapons-the fundamental agreement underlying the NPT. If a country sees others cheating and getting away with it, that country may feel less secure and thus more likely to cheat as well. By limiting Iranian nuclear ambitions, then, a deal has the potential to eliminate-or at least make less salient-a prominent example of a country that appears to be cheating and getting away with it.

This effect is amplified because there are other states in the region that have felt threatened by an unconstrained Iranian nuclear effort. ${ }^{6}$ A deal will not completely reassure Iran's neighbors, given that their concerns over Iran run much deeper than its nuclear program and even the best deal cannot eliminate the possibility of future noncompliance, but it is possible that a nuclear agreement will calm regional nerves somewhat. If Saudi Arabia, the United Arab Emirates (UAE), and others in the region come to see a diminished threat from Iran as a consequence of a deal, this potentially affects the strength of the regime as a whole. ${ }^{7}$ The international community may perceive Iran's neighbors as less likely to pursue their own nuclear weapons programs or adopt nuclear hedging strategies, which makes other countries less likely to consider weapons themselves, and so on. ${ }^{8}$ The ripple effects of this signal extend well beyond Iran's neighbors, to reach potential proliferants globally.

An agreement with Iran may also have the desirable side effect of raising the profile of the Additional Protocol and other enhanced safeguards measures. The Additional Protocol was created as a response to the failure of international nuclear safeguards in Iraq prior to the 1991 Gulf War. For more than a decade, the IAEA had routinely inspected known Iraqi nuclear sites, not realizing that Iraq maintained a clandestine uranium enrichment program in nearby, undeclared facilities that were only discovered after the war. Standard IAEA safeguards measures focus almost entirely on verifying the declarations of states, not on identifying illicit activities. In response to the Iraq case, the IAEA developed the more rigorous safeguards approach embodied in the Additional Protocol, which was finalized in 1997. The Additional Protocol is a voluntary commitment for states, although the United States and other partners have pushed for its universalization. It has now been brought into force by 124 states. ${ }^{9}$ In 2003, Iran signed, but never ratified, the Additional Protocol; its ratification would almost certainly be required by a nuclear deal with the $\mathrm{P} 5+1$. The widespread implementation of the Additional Protocol is important to perceptions of the effectiveness of the regime. It can play a key role in boosting confidence that the nonproliferation regime is capable of detecting states that opt to pursue nuclear weapons, by granting inspectors broader knowledge of and access to nuclear facilities even before nuclear material is present there. Increased international atten- 
tion stemming from a deal with Iran may increase the pressure on notable holdouts—notably Brazil, Argentina, Egypt, and Saudi Arabia - to bring the Additional Protocol into force as well.

The Additional Protocol is just one step in an ongoing effort to increase the effectiveness of monitoring and verification measures within the regime. There are other, less-mentioned factors that complement the Additional Protocol, including the willingness of the IAEA to take a broader view of its legal authority for inspections and other verification measures; the integration of streams of outside information with state declarations and inspection reports; and the implementation of the state-level concept for safeguards, which allows the IAEA to customize verification measures to fit the particular circumstances of the state. The nuclear deal with Iran offers a useful testing ground for the effectiveness of these kinds of enhanced safeguards measures and sets an important precedent for applying these measures elsewhere. As the IAEA gains experience with a more intensive verification regime in Iran, it may be able to apply lessons learned to safeguards in other countries. In addition, if the Iran case demonstrates that these measures are effective, it may help to quiet some opposition among member states that see enhanced safeguards as expanding the IAEA's legal authority and shifting the balance of the agency's responsibilities too far toward nonproliferation at the expense of technical assistance in nuclear technologies.

The agreement with Iran also presents an opportunity to mobilize resources in support of nuclear safeguards. The IAEA's safeguards directorate is already stretched thin-it is clear that the IAEA will need additional resources if it is to take on more responsibility under the terms of the deal with Iran. ${ }^{10}$ If the provision of these resources is handled correctly, it will not just permit enhanced safeguards measures in Iran, it will lay the groundwork for more effective verification measures in other states in the future. This can be achieved partly through organizational efficiencies that may come out of the Iran experience-for example, in better integrating satellite imagery and open-source information into verification procedures - and also through improvements in what might be called safeguards infrastructure, the technical and human resources available for inspections and data analysis. The increasing use of environmental sampling as a safeguards tool, for example, has strained resources at the IAEA's nuclear laboratory in Seibersdorf, Austria. Renovations are underway, but the added resources that might come from the agreement with Iran could speed improvements along, with benefits that spill over into other safeguards cases.

\section{Nuclear Latency, Nuclear Hedging, and the NPT}

In referring Iran to the UN Security Council, the IAEA Board of Governors noted that Iran failed to report nuclear-related material, facilities, and activities as required under its safeguards agreement with the IAEA. ${ }^{11}$ Iran engaged in uranium enrichment and plutonium reprocessing in undeclared facilities in the absence of nuclear safeguards. Iran also provided IAEA inspectors with incomplete and, at times, contradictory explanations of its nuclear activity, and has so far refused to address many ongoing questions about the potential military dimensions of its nuclear program. The IAEA

\section{The agreement with Iran also presents an opportunity to mobilize resources in support of nuclear safeguards.}




\section{Iran's nuclear infrastructure in the days after an agreement will amount to a kind of latent nuclear weapons capability.}

Board of Governors and, later, the UN Security Council, in resolution after resolution, have called for a suspension of Iran's enrichment efforts. ${ }^{12}$ The United States has at times gone further, arguing under the George W. Bush administration that Iran could not be allowed to have any enrichment capability. ${ }^{13}$

In the days after a deal, however, Iran will almost certainly maintain an ability to enrich uranium, albeit under safeguards and with a political agreement limiting the scope of enrichment, including the number and type of centrifuges and level of enrichment. Such a latent nuclear capability in Iran could have a negative impact on the nonproliferation regime. While a deal with Iran is unlikely to launch a full-blown proliferation cascade, in which Egypt, Turkey, and Saudi Arabia pursue nuclear-weapons options, ${ }^{14}$ a deal may cause states to pursue a nuclear hedging strategy—deliberately building up domestic nuclear infrastructure to keep future options open. ${ }^{15}$ This, in turn, may well reduce confidence in the regime overall.

\section{Nuclear Latency Is the New Nuclear Proliferation}

Iran's nuclear infrastructure in the days after an agreement will amount to a kind of latent nuclear weapons capability. If Iran made the decision to develop nuclear weapons, it could repurpose its civilian nuclear facilities, enrich its uranium to weapons grade, and produce enough fissile material for a weapon. How much time such an effort would take is a matter of some debate, but even after a deal Iran may have the ability to produce enough fissile material for a nuclear weapon in a matter of months, rather than years. ${ }^{16}$ The production of weapons-grade fissile material is not the only piece of the nuclear weapons puzzle, but it is the most difficult aspect of nuclear weapons development and also the most likely to be detected by IAEA inspectors. Most of the other necessary tasks related to weapons design and weaponization can be pursued in parallel to fissile material production and with much less risk of detection by the IAEA.

Iran would maintain some level of nuclear latency, of course, with or without a deal. Absent a nuclear agreement, Iran probably could continue to enlarge and improve its centrifuge program, shortening the path to a weapon significantly. A deal would reduce this latency, but would also legitimize it.

Iran's nuclear latency may partially negate some of the nonproliferation benefits of a deal. Although Iran's latent nuclear capability is unlikely to lead to a cascade of new nuclear weapons programs in the region, Iran's neighbors need not pursue nuclear weapons themselves to create additional challenges for the regime. They may elect instead to follow a nuclear hedging strategy, as Iran has done. Saudi Arabia, UAE, and Jordan, for example, have announced their intention to seek nuclear energy programs in the decade since the Iranian program has been a source of conflict. ${ }^{17}$ Even if these states have no intention of developing a weapons program - the UAE and Jordan, in particular, have clear economic reasons for building up their nuclear infrastructure-having some indigenous nuclear technology provides a latent capability that could raise questions about their intentions in the minds of adversaries and provide flexibility in the event that the nuclear agreement fails and Iran ultimately seeks weapons. Such hedging strategies, however, illustrate very clearly a central weakness of the nonpro- 
liferation regime; there are few tools available that are effective in stopping a determined state from building up a latent nuclear capability.

Iran's nuclear latency could well alarm its neighbors even if it shows no intention of cheating on its commitments under the nuclear deal. The closer Iran is to deploying a nuclear weapon, the more tempting it will be for others to mitigate this potential threat by exploring their own options for weapons development or an expanded nuclear infrastructure before it is too late. If a new status quo of Iranian nuclear latency is enough to drive states in the region to investigate nuclear weapons programs or nuclear hedging strategies themselves, then the nuclear nonproliferation regime as a whole is likely to suffer from diminished credibility.

While much of the discussion of Iran's nuclear latency has focused on how long it would take Iran to produce a nuclear weapon, the real time period of interest is how long it would take Iran to produce a weapon from the point at which its break-out efforts are discovered. The latency we care about, then, is a function of both underlying nuclear infrastructure and the strength of monitoring and verification measures in a country. To some extent, concerns about the capabilities that Iran is allowed to maintain in-country can be mitigated by a more robust inspection regime. Put another way, the international community may have a higher threshold for Iran's latent capability should it be accompanied by a more intrusive inspections regime.

Thus, there is no bright line to show the level of nuclear latency beyond which the credibility of the nuclear nonproliferation regime is damaged. Many states will be satisfied if an Iranian nuclear weapons effort has a high probability of detection several months before Tehran could develop a weapon. Others, such as Israel, will be unhappy with any agreement that allows Iran to retain an enrichment capability, no matter how intrusive the inspection regime. The constraints imposed on Iran by a deal should reduce the incentives for its neighbors to pursue nuclear weapons efforts or hedging strategies of their own, but are unlikely to eliminate them entirely. To the extent that states in the region continue to see some utility in pursuing a nuclear hedging strategy, a deal will put some additional strain on the nonproliferation regime.

\section{The Iranian Nuclear Precedent and the Spread of ENR Technology}

Another side effect of a deal is to legitimize the latent nuclear capability that Iran has acquired by virtue of its noncompliance with the rules of the regime. One key aspect of the debate with Iran is its claim of a "right to enrich" under the NPT. After reaching an interim deal in November 2013, Iranian leaders touted their victory in securing their right to enrichment. U.S. diplomats claim the deal does no such thing - the United States has not explicitly recognized enrichment as a right permitted under the NPT. Neither enrichment nor reprocessing is mentioned in the text of the NPT, and whether states have a right to ENR is a long-standing debate among treaty members. Iran's claim that the West is infringing on its rights under the treaty has garnered Tehran some sympathy around the world, especially within the bloc of Non-Aligned

\section{There is no bright line to show the level of nuclear latency beyond which the credibility of the nuclear nonproliferation regime is damaged.}




\section{The Iran case may be a complicating factor even in existing bilateral nuclear cooperation agreements.}

Movement members, ${ }^{18}$ and boosted domestic support for its nuclear program. ${ }^{19}$ Regardless of what U.S. diplomats claim, however, the deal with Iran seems to close the door on this debate for the time being. Iran will maintain that its right to enrich has been validated, in deeds if not in words.

Iran's indigenous capacity to enrich uranium could set a precedent for acquisition of enrichment technologies by other nonnuclear weapons states within the NPT. Enrichment technology is necessary for the domestic production of fuel for nuclear reactors, but the same technology can produce fissile material for nuclear weapons and so is seen as posing a proliferation risk. The United States has long worked to limit the spread of ENR technologies both multilaterally, through the Nuclear Suppliers Group (NSG), and using bilateral nuclear cooperation agreements. ${ }^{20}$

By some measures, efforts to limit ENR have been quite successful. The United States has sought to prevent allies and partners, including South Korea and Taiwan, from obtaining such technology, and in recent years no ENR technology has been supplied to states that do not already possess it. Of the 31 states that produce nuclear energy domestically, only 11 have uranium enrichment technology, and only five reprocess spent nuclear fuel as part of a civilian nuclear program. ${ }^{21}$

The Iran case, along with increased interest in nuclear energy development more generally, has brought new attention to the issue of ENR supply. But once Iran possesses a latent nuclear capability that has been endorsed, however reluctantly, by the $\mathrm{P} 5+1$, it could become more difficult to hold the line against ENR capabilities in other states. Can the United States successfully argue that a trusted ally should be denied ENR, even as Iran, having been found in noncompliance with its nonproliferation commitments, continues to enrich uranium? The terms of the Iran deal thus risk becoming the new floor for indigenous nuclear capability, with nuclear suppliers finding it harder and harder to make the case for limits on these technologies. Future nuclear weapons aspirants probably would not need to endure years of painful sanctions, as Iran has, to achieve latency. Several states-Japan and Brazil, for example_-already have a significant latent nuclear capability, and others can build up nuclear capabilities while remaining in compliance with the NPT as long as they properly declare their activities to the IAEA.

The Iran case may be a complicating factor even in existing bilateral nuclear cooperation agreements. In 2009, for the first time in one of these agreements, the UAE agreed not to possess ENR technology as a condition of cooperation with the United States. For this reason, the UAE deal has been seen as the gold standard for nuclear cooperation agreements. But the UAE agreement also carries a most-favored-nation clause, stipulating that if the United States concludes a more favorable deal with another state in the region, then the UAE could seek to amend the agreement. Because no nuclear cooperation agreement is involved, the nuclear deal with Iran probably would not trigger the most-favored-nation clause. Allowing Iran to maintain the enrichment capabilities that the UAE agreed to forgo, however, could be seen as undermining the spirit of the UAE deal and could thus complicate future attempts to reach agreements that limit ENR supply. 
Of course, the United States is the final arbiter of what bargain will be struck in a bilateral nuclear cooperation agreement; it cannot be forced to allow the transfer of ENR capabilities against its will. There is some reason to be skeptical, however, that the United States will be able to maintain its hard-line stance against the provision of ENR, given the precedent set in the Iran case. Even in the best of circumstances, it has proven difficult to subordinate bilateral relations with important allies or potential partners to the long-term, vague goal of "strengthening" the nuclear nonproliferation regime. U.S. policy has illustrated this difficulty time and again-most notably in recent years with the signing of a nuclear cooperation agreement with India that many saw as a significant blow to the regime. ${ }^{22}$ Armed with the example of an enrichmentcapable Iran, states may be even more aggressive in pressing their claims to host ENR technology. At the very least, the Iran deal has the potential to weaken the U.S. negotiating position somewhat when it comes to the transfer of these capabilities.

While U.S. policy has been to limit ENR transfers even for recipient states that raise no red flags, other supplier states have taken a much more liberal view of nuclear trade. Recently adopted NSG rules on the supply of ENR capabilities-while an improvement over the previous guidelines_-amount to much weaker restrictions than the United States originally proposed. A number of supplier states objected to a blanket ban on ENR sales to states that did not already have the technology, and even to less restrictive criteria that called on suppliers to consider factors like regional stability when making decisions about nuclear transfers. Given the more lenient stance of most nuclear supplier states, the precedent of ENR capability set by the Iran case may be particularly difficult for other players in the NSG to resist. Many of these states are already inclined not to impose conditions on ENR; the Iran case provides additional ammunition for them not to do so.

\section{U.S. Allies and Limits on ENR}

The impact of a deal with Iran on the further spread of ENR technology may make it more difficult for the United States to persuade other states, especially allies, not to pursue this technology. Negotiations over a nuclear cooperation agreement between the United States and South Korea hit an impasse last year over ENR capabilities. ${ }^{23}$ South Korea pushed for U.S. consent to enrich uranium and reprocess spent fuel that has been provided by the United States; the United States objected on nonproliferation grounds. If the United States is perceived as permitting Iran, a state antagonistic to U.S. interests, to continue to engage in enrichment and reprocessing, it could be more difficult to persuade close U.S. allies to accept restrictions on ENR technologies.

The nuclear cooperation agreement is important to both the United States and South Korea. South Korea's nuclear industry is growing quickly, both domestically and as a supplier to other states, and U.S. companies work closely with South Korean counterparts on several projects. Commercial interests aside, South Korea is an important U.S. ally, and a nuclear cooperation agreement is one of the policy priorities of President Park Geun-hye. Balanced against this strong bilateral relationship, however, are the potential

\section{While U.S. policy has been to limit ENR transfers even for recipient states that raise no red flags, other supplier states have taken a much more liberal view of nuclear trade.}




\section{A successful deal with Iran is better for the nuclear nonproliferation regime than the alternative, but policymakers should work to mitigate the potential downsides of an agreement.}

consequences of the nuclear cooperation agreement for proliferation in East Asia and for the nonproliferation regime generally. Continued provocations from the North have led some in South Korea to argue that the country should be seeking nuclear weapons to counter the North Korean threat. ${ }^{24}$ These voices are not yet in the mainstream of South Korean politics, but they do reflect public opinion; two polls conducted after a North Korean nuclear test in February 2013 found about two-thirds of South Koreans support a nuclear weapons effort. ${ }^{25}$

Seoul insists that it has no intention of developing nuclear weapons, arguing that it needs ENR capabilities to ensure a fuel supply for its growing domestic nuclear power industry (as Iran also argues), and to address a rapidly worsening spent fuel storage problem. ENR capabilities might also make South Korea more competitive when it comes to supplying nuclear technology abroad. A South Korean nuclear weapons program would certainly be a negative outcome for nonproliferation efforts, but the South need not seek weapons to pose additional challenges for the regime. If South Korea were ultimately to develop ENR capabilities, it would be seen by many states as part of a hedging strategy designed to enhance Seoul's latent nuclear capability, just as many states view Iran's quest for ENR technology in this way. A percep- tion of the nonproliferation regime as unable to constrain its members' nuclear ambitions is itself damaging, even beyond the immediate threats of nuclear states in the Gulf and in East Asia. Countries feel bound to play by the rules only when they believe others are doing the same; a crisis of confidence in the regime threatens to loosen the constraints of international agreements and make proliferation more likely.

Whatever the outcome, the difficult negotiations with South Korea are likely to be just the first of many tests of the U.S. ability to deny the precedent that would be set by an Iran deal. Seoul is not the only allied capital where clear commercial and bilateral security interests will line up in favor of an agreement that allows an ENR capability. If the United States ultimately consents to ENR provisions, it will then face the task of negotiating the limits on such consent. Here, again, the Iran deal may come into play. The Iranian enrichment effort sprawls across a number of component manufacturing plants, research and development labs, and production facilities, and probably will maintain thousands of operating gas centrifuges in the days after a deal. Given the scale of the Iranian program, placing strict limits on the size of an allied ENR capability may not be easy.

\section{Policy Recommendations for Regime Credibility}

A successful deal with Iran is better for the nuclear nonproliferation regime than the alternative, but policymakers should work to mitigate the potential downsides of an agreement. The United States should continue to hold the line on new states receiving ENR technologies and use the deal as an opportunity to enhance the capabilities of the IAEA and support its more stringent nuclear safeguards measures. Ultimately, the best way to strengthen the 
nonproliferation regime will be to ensure the long-term success of an agreement.

Recognizing that Iran will retain enrichment capabilities under the Iran deal, some analysts have suggested that the P5+1 explicitly indicate in the text of a deal that the agreement is an extraordinary measure that will not set a precedent for other states. ${ }^{26}$ Those other states, however, are unlikely to see this as a persuasive argument. Denying precedent will be particularly difficult in the context of the nuclear nonproliferation regime, which has substantial baggage when it comes to applying different standards to different groups of states. Since the early negotiations for the NPT, nonnuclear countries have bristled at the structure of a treaty that accepts separate classes of nuclear haves and have-nots. Developing states today are unlikely to accept the carving out of a separate category for imminent threats to peace and security. Emphasizing Iran as an exceptional case will only serve to remind states of these perceived double standards and will do little to dissuade those who do perceive a precedent in the deal.

What the United States can do is continue to prevent new states from acquiring indigenous ENR capabilities, through the NSG and its own bilateral nuclear cooperation deals and fuelsupply guarantees. Limiting the spread of ENR capabilities through bilateral supply is a straightforward way to bolster the regime in the wake of the Iran deal.

The United States also should use the deal with Iran to cast a spotlight on the Additional Protocol and the importance of nuclear safeguards. The deal offers an opportunity to shore up the existing safeguards system. The United States and like-minded countries should continue their attempts to persuade states that are resisting the Additional Protocol, but also use the circumstances of the deal to press forward with the IAEA's new state-level concept for safeguards, which looks beyond state declarations to verify that there is no illicit nuclear activity. While the state-level concept has run into opposition from some member states, which see it as overstepping the IAEA's legal authority, Iran is an excellent rationale for new approaches to effective verification of nuclear capabilities. As IAEA inspectors begin to apply new safeguards concepts to their work in Iran under a deal, the United States should work to call attention to the role of the Additional Protocol and other safeguards advances in building confidence in the peaceful nature of Iran's nuclear program. The Iran case may offer a strong illustration of the benefit of strengthened IAEA safeguards for building trust in the regime, by verifying that states are not diverting nuclear material for dangerous purposes.

More generally, the Iran deal is an opportunity for the United States to emphasize the importance of the IAEA for ensuring compliance with the NPT. The IAEA is a relatively small organization with a global mandate. A deal would place a significant burden on the IAEA inspectorate, likely calling for additional inspections to verify both Iranian declarations and the terms of the agreement itself. The P5+1 should take the lead in making sure the IAEA has the resources and technology necessary to take on these additional tasks, and encourage other states to share the resource burden. Strong monitoring and verification pays dividends by boosting confidence in the nonproliferation regime's ability to detect and respond to noncompli-

\section{The United States also should use the deal with Iran to cast a spotlight on the Additional Protocol and the importance of nuclear safeguards.}


ance, and the Iran experience could actually bolster the credibility of the regime if the IAEA's response is seen as effective.

Finally, the P-5+1 should take steps to promote the long-term success of the Iran nuclear deal. Even if Tehran is forthcoming and fully abides by the terms of the agreement, the IAEA is likely to take some time to verify all of Iran's declarations and fully settle outstanding issues with the military side of its nuclear program. ${ }^{27}$ The United States cannot control Iranian actions, but it can ensure that an agreement has the opportunity to succeed by reminding the international community, and especially those in the region, that this will be a long-term process rather than an overnight success. The United States will face real challenges in addressing claims of Iranian cheating that are almost certain to come in the months and years after the deal is signed. The worst-case scenario for global nonproliferation efforts is an agreement that falls apart. In that case, the regime suffers doubly. First, faith in the ability of the international community to effectively and peacefully address NPT noncompliance could be damaged. Adding such an outcome to a track record that includes the failed Agreed Framework - a negotiated deal to freeze the North Korean nuclear program in 1994 - risks undermining the regime's credibility, making it less effective in limiting proliferation in the future. A failed agreement may bolster the case of those who would prefer to work outside the regime to address proliferation, including those who would more quickly resort to the use of force over diplomacy. Second, the regime would still be saddled with the negative precedent of allowing a noncompliant NPT state to maintain a latent nuclear capability, with all the attendant repercussions for future limits on the spread of ENR technology.

A negotiated deal to curtail Iran's nuclear weapons ambitions would represent a major nonproliferation breakthrough. Though a deal carries some costs, it is better than the alternative: an unfettered Iranian nuclear effort that sows conflict and perhaps furthers proliferation in an already unstable region. To make the most of the deal, the United States and its allies should emphasize the relevant benefits for the nuclear nonproliferation regime-the value of universal application of the most stringent IAEA safeguards and the central role of the IAEA in verifying compliance with the NPT. Most importantly, the United States must do everything in its power to permit the IAEA to do its work in Iran, allowing the process sufficient time and space to succeed. 


\section{Notes}

${ }^{1}$ Dalia Dassa Kaye and Jeffrey Martini, The Days After a Deal with Iran: Regional Responses to a Final Nuclear Agreement, Santa Monica, Calif.: RAND Corporation, PE-122-RC, 2014. As of May 15, 2014: http://www.rand.org/pubs/perspectives/PE122.html; Alireza Nader, The Days After a Deal with Iran: Continuity and Change in Iranian Foreign Policy, Santa Monica, Calif.: RAND Corporation, PE-124-RC, 2014. As of June 2014: http://www.rand.org/pubs/perspectives/PE124.html; Lynn E. Davis, The Days After a Deal with Iran: U.S. Policies of Hedging and Engaging, Santa Monica, Calif.: RAND Corporation, PE-125-RC, 2014. As of August 2014: http://www.rand.org/pubs/perspectives/PE125.html; Lynn E. Davis and David E. Thaler, The Days After a Deal with Iran: Implications for the Air Force, Santa Monica, Calif.: RAND Corporation, PE-137-RC, 2015. As of January 2015: http://www.rand.org/pubs/perspectives/PE137.html; Larry Hanauer, The Days After a Deal with Iran: Congress's Role in Implementing a Nuclear Agreement, Santa Monica, Calif.: RAND Corporation, PE-139-RC, 2015. As of January 2015: http://www.rand.org/pubs/perspectives/PE139.html.

${ }^{2}$ Our analysis focuses on two provisions in particular: Iran's conclusion of an Additional Protocol to its IAEA safeguards agreement and its continued enrichment of uranium. While we do not attempt here to predict the exact provisions of a final agreement, we expect that a deal would not be completed without the inclusion of these two items. Our analysis would not change substantially if some of the other assumed provisions were altered.

${ }^{3}$ On the effect of regime credibility on future proliferation, see Jeffrey M. Kaplow, State Compliance and the Track Record of the Nuclear Nonproliferation Regime, Working Paper, 2014. As of September 15, 2014: http://dl.jkaplow.net/KaplowCh1.pdf

${ }^{4}$ For example, despite U.S. pressure, Turkey and Brazil opposed a UN Security Council resolution on sanctioning Iran in 2012, after the West largely rejected a deal they had brokered with Iran. After Indonesia voted in favor of UN Security Council Resolution 1747 against Iran in 2007, its leaders were criticized domestically for their alignment with the United States. Lawmakers used a provision of the Indonesian constitution to compel the President to submit to formal questioning, resulting in months of debate. See Michael S. Malley and Tanya Ogilvie-White, "Nuclear Capabilities in Southeast Asia: Building a Preventive Proliferation Firewall," Nonproliferation Review, Vol. 16, No 1, 2009, p. 32. The politics of the Iranian conflict have also complicated relations with Malaysia. After a long-serving Malaysian envoy to the IAEA voted against a resolution criticizing Iran in 2010, the Malaysian government quickly replaced him amid pressure from the United States. Mark Heinrich, "Malaysia Dismissed IAEA Envoy After Iran Atomic Vote," Reuters, February 9, 2010.

${ }^{5}$ Examples include Joshua Williams and Jon B. Wolfstahl, The NPT at 35: A Crisis of Compliance or a Crisis of Confidence? New York: Carnegie Endowment for International Peace, 2005; Tom Sauer, "The Nuclear Nonproliferation Regime in Crisis," Peace Review, Vol. 18, No. 3, 2006, pp. 333-340; and George Perkovich, "The End of the Nonproliferation Regime?" Current History, Vol. 105, No. 694, 2006, pp. 355-362. One scholar's "short list" of challenges to the NPT includes ten external and nine internal factors; see William C. Potter, "The NPT and the Sources of Nuclear Restraint," Daedalus, Vol. 139, No. 1, 2010 , pp. 68-81.

${ }^{6}$ For more on regional responses to a nuclear agreement with Iran, see Kaye and Martini, 2014.

${ }^{7}$ Israel's response to a deal with Iran does not affect the nonproliferation regime in the same way, because Israel already possesses nuclear weapons. How Israel perceives the threat from Iran in the days after a deal, however, is an important factor in overall regional security. For a complete discussion, see Kaye and Martini, 2014.

${ }^{8}$ We recognize that states proliferate for a variety of reasons beyond that of a proliferating neighbor (e.g., prestige, bureaucratic interests, psychological dispositions of leaders), but there is evidence that a proliferating neighbor or rival increases the likelihood that a state will explore a nuclear weapons option. The perception that states are exploring a nuclear weapons option could be damaging to the nuclear nonproliferation regime. On the finding that states proliferate in response to neighbors or rivals, see Nicholas L. Miller, “Nuclear Dominoes: A Self-Defeating Prophecy?” Security Studies, Vol. 23, No. 1, 2014, pp. 33-73.

9 International Atomic Energy Agency, "Conclusion of Additional Protocols: Status as of 5 November 2014," web page, 2014. As of December 15, 2014: https://www.iaea.org/safeguards/documents/AP_status_list.pdf

${ }^{10}$ Andreas Persbo, A Reflection on the Current State of Nuclear Non-Proliferation and Safeguards, EU Non-Proliferation Consortium, Non-Proliferation Papers, No. 8, February 2012, p. 15. 
${ }^{11}$ IAEA Board of Governors, "Implementation of the NPT Safeguards Agreement in the Islamic Republic of Iran," IAEA GOV/2006/14, February 4, 2006. As of September 1, 2014: https://www.iaea.org/sites/default/files/gov2006-14.pdf

${ }^{12}$ For example, UN Security Council Resolution 1696, adopted in 2006, "demanded that Iran suspend all enrichment-related and reprocessing activities." United Nations, "Security Council Demands Iran Suspend Uranium Enrichment by 31 August, or Face Possible Economic, Diplomatic Sanctions,” July 31, 2006. As of September 2014: http://www.un.org/News/Press/docs/2006/sc8792.doc.htm

13 "Bush: Iran Must Stop Uranium Enrichment," CNN.com, June 19, 2006.

${ }^{14}$ On skepticism of an Iranian bomb causing a "nuclear cascade" in the region see, for example, Thomas W. Lippman, Nuclear Weapons and Saudi Strategy, The Middle East Institute Policy Brief No. 5, January 2008; Colin H. Kahl, Melissa G. Dalton, and Matthew Irvine, Atomic Kingdom: If Iran Builds the Bomb, Will Saudi Arabia Be Next? Center for New American Security, February 2013. On nuclear domino theories in general, see Johan Bergenas, "The Nuclear Domino Myth: Dismantling WorstCase Proliferation Scenarios," Foreign Affairs, August 31, 2010.

${ }^{15}$ On nuclear latency, see Scott D. Sagan, "Nuclear Latency and Nuclear Proliferation," in William Potter and Gaukar Mukhatzhanova, eds. Forecasting Proliferation in the 21st Century: the Role of Theory, Palo Alto, Calif.: Stanford University Press, 2010, pp. 13-37. On the concept of nuclear hedging, see Ariel Levite, "Never Say Never Again: Nuclear Reversal Revisited," International Security, Vol. 27, No. 3, Winter 2002/03, pp. 59-88.

${ }^{16}$ David E. Sanger, “Building Nuclear Weapon Would Take Years, Not Months, Iran Says in Report," New York Times, June 13, 2014.

${ }^{17}$ The six members of the Gulf Cooperation Council—Kuwait, Saudi Arabia, Bahrain, the United Arab Emirates, Qatar and Oman—announced their intention to commission a study on peaceful nuclear energy in December 2006. Jordan created a national Committee for Nuclear Strategy in 2007. Egypt showed renewed interest in nuclear energy in 2004, signing a nuclear cooperation deal with Russia, and a second cooperation deal with the Russians was signed in 2008.

${ }^{18}$ Thomas Erdbrink, “Nonaligned Nations Back Iran’s Nuclear Bid, but Not Syria," New York Times, August 31, 2012.

${ }^{19}$ In a 2009 survey conducted by the RAND Corporation, Iranians overwhelmingly supported Iran's civilian nuclear program. See Sara Beth Elson and Alireza Nader, What Do Iranians Think? A Survey of Attitudes on the United States, the Nuclear Program, and the Economy, Santa Monica, Calif.: RAND Corporation, TR-910, 2011. As of December 17, 2014: http://www.rand.org/pubs/technical_reports/TR910.html

${ }^{20}$ On U.S. efforts to promote nuclear non-proliferation, see R. Davis Gibbons, Baruch to Barack: Hegemony and the Politics of the Nuclear Non-Proliferation Regime, Working Paper, 2014. As of December 20, 2014: http://www.rebeccadavisgibbons.com/\#!research/clol0

${ }^{21}$ Figures are from the World Nuclear Association website, undated. As of September 15, 2014: http://www.world-nuclear.org. Several additional states have reprocessing capabilities as part of a nuclear weapons program. Not counted here are the handful of states, including Iraq and Libya, that have investigated uranium enrichment technology in the past.

${ }^{22}$ See, for example, William C. Potter, "India and the New Look of US Nonproliferation Policy," Nonproliferation Review, Vol. 12, No. 2, 2005 , pp. 343-354.

${ }^{23}$ For background on the U.S.-South Korea nuclear cooperation negotiations, including reporting that the sides may be nearing a deal, see Duyeon Kim, "Beyond the Politics of the U.S.-South Korea 1-2-3 Agreement," Carnegie Endowment for International Peace, October 29, 2014. As of November 15, 2014:

http://carnegieendowment.org/2014/10/29/beyond-politics-of-u.s.-south-korea-123-agreement/ht2o

${ }^{24}$ See, for example, David E. Sanger, “In the U.S., South Korean Makes Case for Nuclear Arms," New York Times, April 9, 2013.

${ }^{25}$ Martin Fackler and Choe Sang-Hun, “South Korea Flirts With Nuclear Ideas as North Blusters,” New York Times, March 10, 2013.

${ }^{26}$ Matthew Kroenig and Barry Pavel, “A Nuclear Deal with Iran: The Proliferation Challenge," National Interest, July 1, 2014.

${ }^{27}$ By comparison, the IAEA undertook four years of inspections in South Africa to verify that the country had, in fact, dismantled its nuclear weapons program, even while receiving high levels of cooperation from the South Africans. 


\section{About the Authors}

Jeffrey M. Kaplow is a Fellow with the University of California's Institute on Global Conflict and Cooperation and a Ph.D. candidate in political science at the University of California, San Diego. He was a 2012-2013 Stanton Nuclear Security Fellow at the RAND Corporation. His current book project explores the effects of international security institutions on state behavior. Kaplow holds a master's degree in political science from the University of California, San Diego, a master's degree in international security policy from Harvard's Kennedy School, and a B.A. in political science from Yale.

Rebecca Davis Gibbons is a Ph.D. candidate in the Government Department at Georgetown University. Her dissertation project, "Baruch to Barack: American Hegemony and the Politics of the Nuclear Nonproliferation Regime" examines variation in nonproliferation cooperation among members of the Treaty on the Nonproliferation of Nuclear Weapons. She was a 2013-2014 Stanton Nuclear Security Fellow at the RAND Corporation. Gibbons has provided support to the Air Force's Strategic Stability and Combatting WMD Branch since 2008. She holds a master's degree in International Security from Georgetown University and a B.A. in Psychological and Brain Sciences from Dartmouth College. 


\section{About This Perspective}

One of a series of RAND Perspectives on what the Middle East and U.S. policy might look like in the "the days after a deal" (a final nuclear agreement) with Iran, this Perspective examines the implications of a potential deal for the nuclear nonproliferation regime. Other papers in the series examine the effect of a deal on the region, Iranian foreign policy, and U.S.-Iran relations.

The authors would like to thank Mark Fitzpatrick and James Quinlivan for their thoughtful review of the draft manuscript. We have also benefited from the helpful comments of Seth Jones, Dalia Dassa Kaye, Bonny Lin, Jeffrey Martini, and Alireza Nader. We are especially grateful to Lynn Davis for her guidance and careful review of multiple drafts. Special thanks are due to those involved in producing this Perspective: Arwen Bicknell, Matthew Byrd, and Lovancy Ingram.

This research was prepared as part of the Stanton Nuclear Security Fellows Program at the RAND Corporation. The Stanton Nuclear Security Fellows Program was created to stimulate the development of the next generation of leaders on nuclear security by supporting interdisciplinary research that will advance policy-relevant understanding of the issues. Fellows carry out a year-long period of independent research, producing studies that contribute to the general body of knowledge on nuclear security.

Stanton Fellows are supported by the Stanton Foundation, created by former CBS President Frank Stanton, the pioneering executive who led the television network for 25 years. In 1954, President Dwight Eisenhower appointed Stanton to a committee convened to develop the first comprehensive plan for the survival of the United States following a nuclear attack. Stanton led the effort to develop plans for national and international communication in the aftermath of a nuclear incident. Stanton also served as chairman (1961-67) and member (1957-78) of the RAND Corporation Board of Trustees. The Stanton Foundation aims, through its support of the nuclear security fellows program, to perpetuate his efforts to meet these challenges. For more information about the Stanton Fellowship at RAND, visit www.rand.org/about/edu_op/fellowships/stanton-nuclear.html.

\section{Limited Print and Electronic Distribution Rights}

This document and trademark(s) contained herein are protected by law. This representation of RAND intellectual property is provided for noncommercial use only. Unauthorized posting of this publication online is prohibited. Permission is given to duplicate this document for personal use only, as long as it is unaltered and complete. Permission is required from RAND to reproduce, or reuse in another form, any of our research documents for commercial use. For information on reprint and linking permissions, please visit www.rand.org/pubs/permissions.html.

The RAND Corporation is a research organization that develops solutions to public policy challenges to help make communities throughout the world safer and more secure, healthier and more prosperous. RAND is nonprofit, nonpartisan, and committed to the public interest.

RAND's publications do not necessarily reflect the opinions of its research clients and sponsors. 


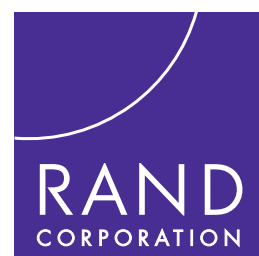

CHILDREN AND FAMILIES

EDUCATION AND THE ARTS

ENERGY AND ENVIRONMENT

HEALTH AND HEALTH CARE

INFRASTRUCTURE AND TRANSPORTATION

INTERNATIONAL AFFAIRS

LAW AND BUSINESS

NATIONAL SECURITY

POPULATION AND AGING

PUBLIC SAFETY

SCIENCE AND TECHNOLOGY

TERRORISM AND HOMELAND SECURITY
The RAND Corporation is a nonprofit institution that helps improve policy and decisionmaking through research and analysis.

This electronic document was made available from www.rand.org as a public service of the RAND Corporation.

\section{Support RAND}

Browse Reports \& Bookstore

Make a charitable contribution

\section{For More Information}

\author{
Visit RAND at www.rand.org \\ Explore the RAND Corporation \\ View document details
}

\section{Perspectives}

RAND perspectives (PEs) present informed perspective on a timely topic that address the challenges facing the public and private sectors. All RAND perspectives undergo rigorous peer review to ensure high standards for research quality and objectivity.

\section{Limited Electronic Distribution Rights}

This document and trademark(s) contained herein are protected by law as indicated in a notice appearing later in this work. This electronic representation of RAND intellectual property is provided for non-commercial use only. Unauthorized posting of RAND electronic documents to a non-RAND website is prohibited. RAND electronic documents are protected under copyright law. Permission is required from RAND to reproduce, or reuse in another form, any of our research documents for commercial use. For information on reprint and linking permissions, please see RAND Permissions. 